\title{
Improved virtual flux direct power control of three phase PWM rectifier using SOGI-FLL estimator under disturbed voltage conditions
}

\author{
A Rahab, H Benalla, F Senani \\ Laboratoire de l'Electrotechnique de Constantine (LEC), Faculté des Sciences de la Technologie, Université des Frères \\ Mentouri de Constantine 1, Algerie
}

\begin{tabular}{l} 
Article Info \\
\hline Article history: \\
Received Oct 17, 2018 \\
Revised Dec 20, 2018 \\
Accepted Dec 31, 2018 \\
\hline
\end{tabular}

Keywords:

Disturbed grid voltage

DPC

SOGI-FLL

Three phase rectifier

Virtual flux estimation

\begin{abstract}
In this paper, improved sonsorless direct power control (DPC) of three-phase rectifiers is presented. The new system are based on virtual flux (VF) and notch filter using Second Order Generalized Integrator frequency located loop SOGI-FLL estimator. In order to improve the VF-DPC performance of PWM rectifier, an improved observation method of virtual flux-linkage is proposed. To avoid the relevant problems of pure integrator, and to achieve the accurate observation of the grid voltage's phase, (SOGI-FLL) are used to displace the pure integrator. Theoretical principles of this method are presented and discussed. These strategies are also investigated under disturbed grid voltage. A theoretical analysis of active and reactive power under a non-ideal source is clearly demonstrated. In order to calculate the compensated powers, the extraction of positive, negative, and harmonic sequences of voltage and current is needed and a multiple dual SOGI-FLL method is used for rapid and accurate extraction. It is shown that the VFDPC with integrating notch filter exhibits several advantages, particularly providing small ripple of DC-link voltage and sinusoidal line current when the supply voltage is not ideal.
\end{abstract}

Copyright $\odot 2019$ Institute of Advanced Engineering and Science. All rights reserved.

\section{Corresponding Author:}

A Rahab,

Laboratoire de l'Electrotechnique de Constantine (LEC),

Faculté des Sciences de la Technologie, Université des frères Mentouri de Constantine 1,

Ain el-bey 25000 Constantine, Algerie.

Email: rahababderezzak@gmail.com

\section{INTRODUCTION}

Research on three-phase (AC/DC) converters) has grown rapidly in recent years because of some important advantages, such as power regeneration capabilities, DC link voltage control, bi-directional power flow, low harmonic distortion of input currents and high power factor [1]. Recently, due to the strong increase in renewable energy sources connected to the grid, more and more converters are used in wind turbines and solar generator. At the same time, high power application in these renewable energy systems requires converters to operate more effectively in improving power quality and the transient stability [2].Therefore, advanced control techniques are very necessary to fulfill these standards.

Diverse control strategies have been proposed in recent work on the PWM rectifier, can be classified, as cited in the literature as a vector oriented control (VOC) and direct power control (DPC) [3], the vector control (VC) can be either based on grid voltage [4-6] or virtual flux (VF) using proportional integral (PI) controllers [7]. However, it has some drawbacks, such as its dependence on the variation of the parameters of the system that its performance depends largely on the adjustment of PI parameters [8]. advantageous control, namely the direct power control (DPC) has been developed in order to overcome the complications due to current control loops [9]. The DPC is based on the instantaneous active and reactive 
power control loops has simple algorithm (no internal current control no rotating coordinates transformations is required), excellent dynamic response ,high power factor, and so on [10-11]. In general, those control techniques require three types of sensors (DC voltage sensor, ac current sensors for input current control, $\mathrm{AC}$ voltage sensors for obtaining the current phase reference), which not only increases the volume of the system device, improves the system cost, but also reduces the system reliability [11].

Direct power control without line voltage sensors is investigated. This sensorless method is based on definition and estimation virtual flux, The three-phase rectifier can be seen as a virtual AC motor, its virtual flux-linkage can be used to estimate the voltage of rectifier, in the conventional virtual flux (VF) estimation of three-phase rectifier,But in the conventional (VF) estimation, there exists a pure integral link, and then the estimation process of (VF) is automatically affected by the initial value and the cumulative deviation of the integrator [11-17]. For solving pure integration problems, more researchers are focusing on replacing the pure integrator by using low-pass filters (LPFs), in which case the pure integrator initial value problem can be solved with success [11], [15-17] but, the problem of amplitude and phase deviation is caused. In order to dominate the influence of its problems, several authors propose methods of estimation of the (VF)], diverse authors propose technique of estimation of the (VF) such as [12], [18]. In summary, the key to a successful operation of the DPC utilizing grid (VF) estimation is dependent on the effectiveness of the (VF) estimation procedure and the selection of the converter switching states [19].

This paper presents a theoretical background study and simulation of DPC based on grid (VF) estimation methods for the three-phase bidirectional PWM rectifier that is inherently capable of handling these problems. The suggested method is based on utilizing the (SOGI) estimator reported in [15-17] and improved switching table defined in [20], the method has the advantages (stable and smooth (VF) estimated, sector detection with high precision, lowering sampling frequency, good performance under disturbed grid voltage, no ac voltage sensors are needed, therefore the cost can be reduced). This paper is organized as follows: mathematical model of three-phase PWM rectifier is described in Section 2. In section 3 presents the VFDPC using Second Order Generalized Integrator frequency located loop (SOGI-FLL) system configuration and gives basic relations of virtual flux and powers estimators and proposed modified virtual flux direct power control (MVFDPC) with integrating notch DC-link output voltage filter when we have under distrubed grid voltage, Section 4 presented simulation results and discussion, finally the conclusion are provided in section 5 .

\section{MODEL OF THREE-PHASE PWM CONVERTER}

The basic block scheme of the VF based DPC system is shown in Figure 1, the three-phase PWM rectifier is controlled using a VFDPC based SOGI-FLL flux estimation and improved switching table (IST) developped in [20].

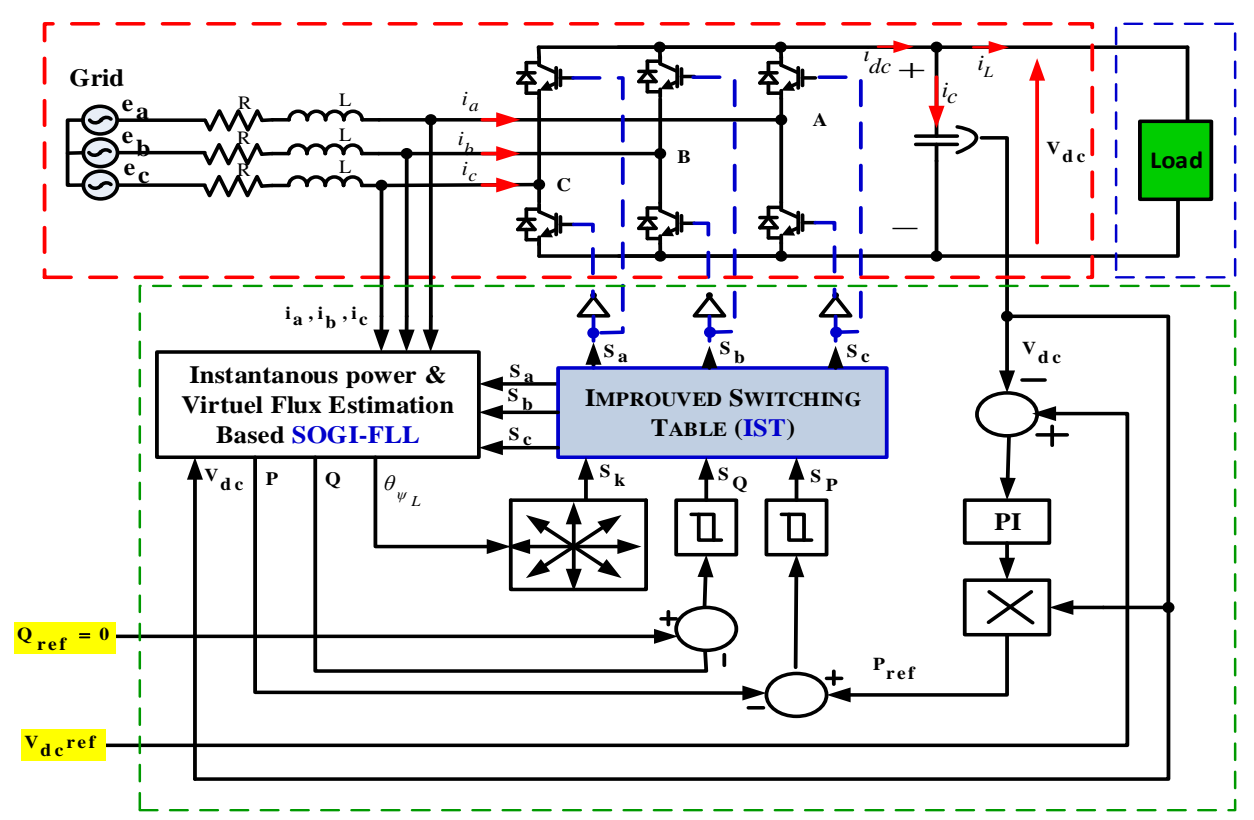

Figure 1. Block diagram for three-phase PWM rectifier 
By assuming balance main grid voltage, the mathematical model of PWM rectifier represent by the red color box in Figure 1 can be described by (1), (2) and (3) [10].

$\left[\begin{array}{l}e_{a} \\ e_{b} \\ e_{c}\end{array}\right]=R\left[\begin{array}{l}i_{a} \\ i_{b} \\ i_{c}\end{array}\right]+L \frac{d}{d t}\left[\begin{array}{l}i_{a} \\ i_{b} \\ i_{c}\end{array}\right]+\left[\begin{array}{l}V_{A} \\ V_{B} \\ V_{C}\end{array}\right]$

$\left\{\begin{array}{c}V_{A}=\frac{V_{d c}}{3}\left(2 S_{a}-S_{b}-S_{c}\right) \\ V_{B}=\frac{V_{d c}}{3}\left(-S_{a}+2 S_{b}-S_{c}\right) \\ V_{C}=\frac{V_{d c}}{3}\left(-S_{a}-S_{b}+2 S_{c}\right)\end{array}\right.$

$C_{d c} \frac{d V_{d c}}{d t}=S_{a} i_{a}+S_{b} i_{b}+S_{c} i_{c}-i_{L}$

Where: $L$ and $R$ are the inductance and resistance of the chokes, respectively ea,eb,ec,ia, $i b$ and $i c$ are the electrical grid voltage and current $, V_{A}, V_{B}, V_{C}$ are the AC side voltages of the rectifier, $V d c$ is the DC bus voltage , $C_{d c}$ is the dc link capacitance, $i L$ the load current $S a, S b$ and $S c$ are the switching states of the rectifier show in Figure 1.

\section{THE CONTROL PRINCIPE OF THREE-PHASE PWM RECTIFIER BASED (DSOGI-FLL)}

3.1. Virtual flux based direct power control (VFDPC)

The (VF) concept which relates the grid voltage and the ac-side inductors to a virtual ac motor hence; $R$ and $L$ represent the stator resistance and the stator leakage resistance of the virtual motor. The lineto-line grid voltages $e_{a b}, e_{b c}, e_{c a}$ would be induced by a virtual air gap flux. In other perspective, the integration of the line voltages leads to a virtual line vector $\Psi_{L .}$ [5], [10-11].

The command active power ( $P_{\text {ref }}$ )and reactive power $\left(\mathrm{Q}_{\text {ref }}\right)$ are compared with the estimated $P$ and $Q$ values via active and reactive power hysteresis controllers, respectively. The digitized output signals $\left(S_{P}\right)$ and $\left(S_{Q}\right)$ and the VF vector position $\left(\theta_{\psi L}\right)$ are used to select the appropriate voltage vector according to the switching table defined in [20]. The advantage of choosing this improved table because it gives the best results, reducing the total harmonic distortion (THD) of line currents and switching losses [20].

\subsubsection{Power estimation based on virtual flux}

The VF components are calculated in stationary $(\alpha-\beta)$ coordinates system as [11].

$$
\begin{aligned}
& \psi_{L \alpha}=\int\left(u_{\text {conco }}+L \frac{d i_{L \alpha}}{d t}\right) d t \\
& \psi_{L \beta}=\int\left(u_{\text {conv } \beta}+L \frac{d i_{\beta}}{d t}\right) d t
\end{aligned}
$$

Then, (6) and (7) are used to estimate the active and reactive power [10].

$$
\begin{aligned}
& P=\omega\left(\psi_{L \alpha} i_{L \beta}-\psi_{L \beta} i_{L \alpha}\right) \\
& Q=\omega\left(\psi_{L \alpha} i_{L \alpha}+\psi_{L \beta} i_{L \beta}\right)
\end{aligned}
$$

The VF vector position:

$$
\theta_{\psi_{L}}=\tan ^{-1}\left(\frac{\psi_{L \alpha}}{\psi_{L \beta}}\right)
$$

is used in VF-DPC scheme to select the appropriate converters voltage vector according to the improved switching table defined in [20]. 


\subsubsection{SOGI-FLL flux estimation}

\section{a. Structure of SOGI}

The structure of the SOGI is shown on Figure 2(a) the first output $\left(u^{\prime}\right)$ of the SOGI is in phase and with the same amplitude with the input $(u)$, the second output $\left(q u^{\prime}\right)$ is shifted of $90^{\circ}$ with the same amplitude, (the letter ' $q$ ' is for indicating that this output is in quadrature with $(u$ '). The two output can then be used for computing magnitude and phase of input $(u) . K$ is the damping Factor of the filter, a gain of great value gives a quick response but can affect the accuracy of the filter and a gain of low value can cause a very long transient response. Then, taking into account all these circumstances the value optimal of gain $\mathrm{K}$ is $(\sqrt{2})[15-16]$.

\section{b. Frequency locked loop (FLL)}

The frequency-locked loop (FLL) structure, shown in Figure 2(b) can be used to measure the angular frequency $\omega$ of the input signal $v$ (in this case, $\omega$ ' is the output or estimated angular frequency of the input signal $(u)$ without using trigonometric functions and making easier its implementation in conventional microcontrollers [21-22].
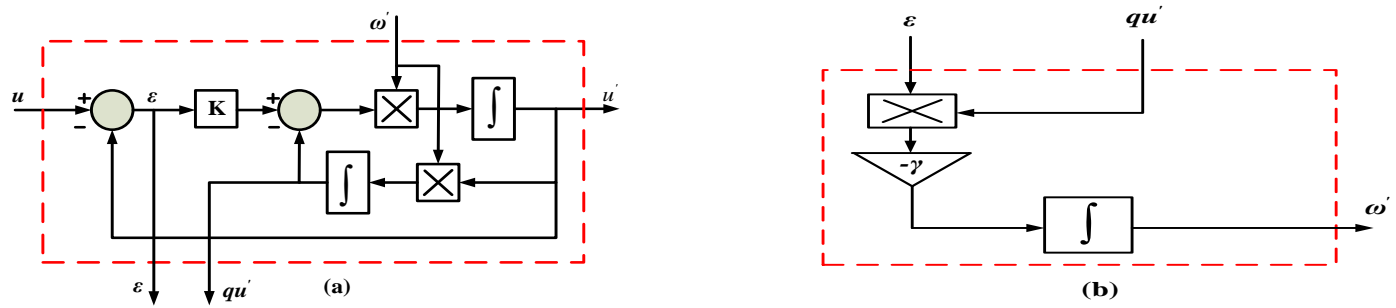

Figure 2. Block diagrams (a) SOGI-QSG scheme, (b) FLL block

The introduction of the FLL allows to adapt the input frequency of the SOGI with the frequency of the signal is filtered. The SOGI account as a good solution for the estimation of the (VF) under a disturbed network. As already seen previously, the second output of the SOGI is a signal of the same amplitude to that of the input but shift of $90^{\circ}$, So we can use the SOGI to integrate (4),(5)and by consequence estimate the virtual flux [14].

Under a balanced and unbalanced grid voltage, the VF can be estimated by SOGI-FLL as illustrated in Figure 3(a) and 3(b). Where RVC: resistance voltage compensation, IFC: inductance flux compensation, PNSC: The positive and negative sequence component devloped in [22]. Under unbalanced source voltages and contains harmonics, the (VF) can be estimated by multiple second order generalized integrators (MSOGI) as illustrated [22].

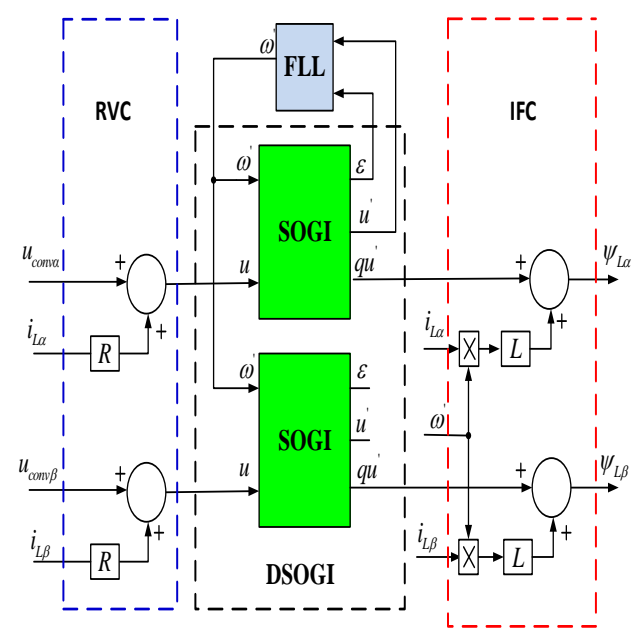

(a)

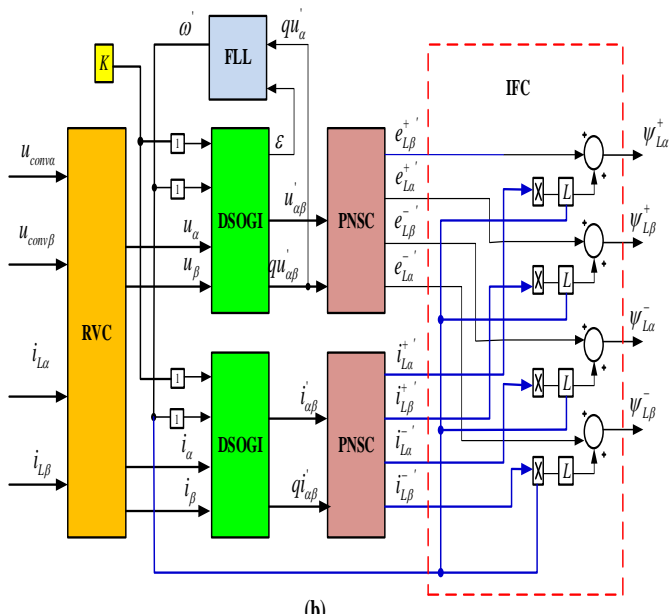

(b)

Figure 3. (a) Virtual flux estimator under balanced grid voltage using SOGI-FLL (b) Virtual flux estimator under unbalanced grid voltage using DSOGI-FLL 


\subsection{Modified virtual flux direct power control MVFDPC}

In stationary reference frames, when the grid voltage unbalanced and distorted, the voltage and current of grid are expressed in (8), (9). The sum of the currents will always be zero (in this analysis assume a three-wire connection system), as a result, the zero sequences of the currents will be zero. In this work, only unbalance and 5th order harmonic components in the supply voltage are taken into account in modeling .

$$
\begin{aligned}
& E_{\alpha \beta}=e_{\alpha}+j e_{\beta}=\left(e_{\alpha}^{+}+e_{\alpha}^{-}+e_{\alpha}^{5}\right)+j\left(e_{\beta}^{+}+e_{\beta}^{-}+e_{\beta}^{5}\right) \\
& I_{\alpha \beta}=i_{\alpha}+j i_{\beta}=\left(i_{\alpha}^{+}+i_{\alpha}^{-}+i_{\alpha}^{5}\right)+j\left(i_{\beta}^{+}+i_{\beta}^{-}+i_{\beta}^{5}\right) \\
& \psi_{\alpha \beta}=\psi_{\alpha}+j \psi_{\beta}=\left(\psi_{\alpha}^{+}+\psi_{\alpha}^{-}+\psi_{\alpha}^{5}\right)+j\left(\psi_{\beta}^{+}+\psi_{\beta}^{-}+\psi_{\beta}^{5}\right)
\end{aligned}
$$

After substituting the flux and current by their values shown in (9) and (10), the active and reactive powers results can be regrouped in four term.

$$
\begin{aligned}
P & =\frac{3}{2}\left(\begin{array}{l}
\omega\left(\psi_{L \alpha}^{+} i_{L \beta}^{+}-\psi_{L \beta}^{+} i_{L \alpha}^{+}+\psi_{L \alpha}^{-} i_{L \beta}^{-}-\psi_{L \beta}^{-} i_{L \alpha}^{-}+\psi_{L \alpha}^{5} i_{L \beta}^{5}-\psi_{L \beta}^{5} i_{L \alpha}^{5}\right)+\omega\left(\psi_{L \alpha}^{+} i_{L \beta}^{-}-\psi_{L \beta}^{+} i_{L \alpha}^{-}+\psi_{L \alpha}^{-} i_{L \beta}^{+}-\psi_{L \beta}^{-} i_{L \alpha}^{+}\right)+ \\
\omega\left(\psi_{L \alpha}^{+} i_{L \beta}^{5}-\psi_{L \beta}^{+} i_{L \alpha}^{5}+\psi_{L \alpha}^{5} i_{L \beta}^{+}-\psi_{L \beta}^{5} i_{L \alpha}^{+}\right)+\omega\left(\psi_{L \alpha}^{5} i_{L \beta}^{-}-\psi_{L \beta}^{5} i_{L \alpha}^{-}+\psi_{L \alpha}^{-} i_{L \beta}^{5}-\psi_{L \beta}^{-} i_{L \alpha}^{5}\right)
\end{array}\right) \\
Q & =\frac{3}{2}\left(\begin{array}{l}
\omega\left(\psi_{L \alpha}^{+} i_{L \alpha}^{+}+\psi_{L \beta}^{+} i_{L \beta}^{+}+\psi_{L \alpha}^{-} i_{L \alpha}^{-}+\psi_{L \beta}^{-} i_{L \beta}^{-}+\psi_{L \alpha}^{5} i_{L \alpha}^{5}+\psi_{L \beta}^{5} i_{L \beta}^{5}\right)+\omega\left(\psi_{L \alpha}^{+} i_{L \alpha}^{-}+\psi_{L \beta}^{+} i_{L \beta}^{-}+\psi_{L \alpha}^{-} i_{L \beta}^{+}+\psi_{L \beta}^{-} i_{L \beta}^{+}\right)+ \\
\omega\left(\psi_{L \alpha}^{+} i_{L \alpha}^{5}+\psi_{L \beta}^{+} i_{L \beta}^{5}+\psi_{L \alpha}^{5} i_{L \alpha}^{+}+\psi_{L \beta}^{5} i_{L \beta}^{+}\right)+\omega\left(\psi_{L \alpha}^{5} i_{L \alpha}^{-}+\psi_{L \beta}^{5} i_{L \beta}^{-}+\psi_{L \alpha}^{-} i_{L \alpha}^{5}+\psi_{L \beta}^{-} i_{L \beta}^{5}\right)
\end{array}\right)
\end{aligned}
$$

There are many control laws that can be applied in the proposed control, to obtain sinusoidal and balanced line currents, the negative sequence component's and 5th harmonic sequence must be eliminated. Therefore, in order to:

$$
\begin{aligned}
& \boldsymbol{i}_{\boldsymbol{L} \alpha}^{-}=\boldsymbol{i}_{\boldsymbol{L} \boldsymbol{\beta}}^{-}=\boldsymbol{i}_{\boldsymbol{L} \boldsymbol{\alpha}}^{5}=\boldsymbol{i}_{\boldsymbol{L} \boldsymbol{\beta}}^{5}=\boldsymbol{O}, \\
& P=\frac{3}{2} \omega\left(\psi_{L \alpha}^{+} i_{L \beta}^{+}-\psi_{L \beta}^{+} i_{L \alpha}^{+}+\psi_{L \alpha}^{-} i_{L \beta}^{+}-\psi_{L \beta}^{-} i_{L \alpha}^{+}+\psi_{L \alpha}^{5} i_{L \beta}^{+}-\psi_{L \beta}^{5} i_{L \alpha}^{+}\right) \\
& Q=\frac{3}{2} \omega\left(\psi_{L \alpha}^{+} i_{L \alpha}^{+}+\psi_{L \beta}^{+} i_{L \beta}^{+}+\psi_{L \alpha}^{-} i_{L \beta}^{+}+\psi_{L \beta}^{-} i_{L \beta}^{+}+\psi_{L \alpha}^{5} i_{L \alpha}^{+}+\psi_{L \beta}^{5} i_{L \beta}^{+}\right)
\end{aligned}
$$

Under the balanced and perfectly sinusoidal grid voltage supply, there only exists a positive sequence component, and the powers can be described as:

$$
\begin{aligned}
& P=\frac{3}{2} \omega\left(\psi_{L \alpha}^{+} i_{L \beta}^{+}-\psi_{L \beta}^{+} i_{L \alpha}^{+}\right) \\
& Q=\frac{3}{2} \omega\left(\psi_{L \alpha}^{+} i_{L \alpha}^{+}+\psi_{L \beta}^{+} i_{L \beta}^{+}\right)
\end{aligned}
$$

From (13) and (14) that we want to eliminate the effect of the negative sequence and 5th order harmonic components of the grid; the terms of active and reactive power compensated can be obtained as:

$$
P_{\text {comp }}=-\frac{3}{2} \omega\left(\psi_{L \alpha}^{-} i_{L \beta}^{+}-\psi_{L \beta}^{-} i_{L \alpha}^{+}+\psi_{L \alpha}^{5} i_{L \beta}^{+}-\psi_{L \beta}^{5} i_{L \alpha}^{+}\right)
$$


$Q_{\text {comp }}=-\frac{3}{2} \omega\left(\psi_{L \alpha}^{-} i_{L \beta}^{+}+\psi_{L \beta}^{-} i_{L \beta}^{+}+\psi_{L \alpha}^{5} i_{L \alpha}^{+}+\psi_{L \beta}^{5} i_{L \beta}^{+}\right)$

Several applications require (smooth, stable and small ripple) of DC-LINK voltage, to obtain sinusoidal ,balanced line currents, and smooth DC- link voltage, the original referenced power $\left(\mathrm{P}_{\text {const }}\right)$ is obtained through measured and filtered DC-link voltage with notch filter Figure 4. The integration of the notch filter in the control scheme, improved the waveform of the DC-link voltage.

Figure 4 show the modified DPC strategy, this schem based on the idea of injecting the active and reactive power compensated components in the original referenced power $\left(P_{\text {const }}\right.$ and $Q_{\text {const })}$ to achieve sinusoidal, symmetric ligne current and smooth DC-link voltage.

The notch filter on the DC link voltage is there in order to remove $(100 \mathrm{~Hz}$ and $300 \mathrm{~Hz})$ oscillations that arise during disturbed voltages conditions. Therefore, these filters ameliorate technique of conventional DPC. A filter that removes the $(100 \mathrm{~Hz}$ and $300 \mathrm{~Hz})$ oscillations can be made by using a SOGI tuned to $(100 \mathrm{~Hz}$ and $300 \mathrm{~Hz})$ instead of $50 \mathrm{~Hz}$. One can subtract the input signal with the filtered signal from the SOGI [23].

$$
\begin{aligned}
& P_{\text {ref }}=P_{\text {const }}+P_{\text {comp }} \\
& Q_{\text {ref }}=Q_{\text {const }}+Q_{\text {comp }}
\end{aligned}
$$

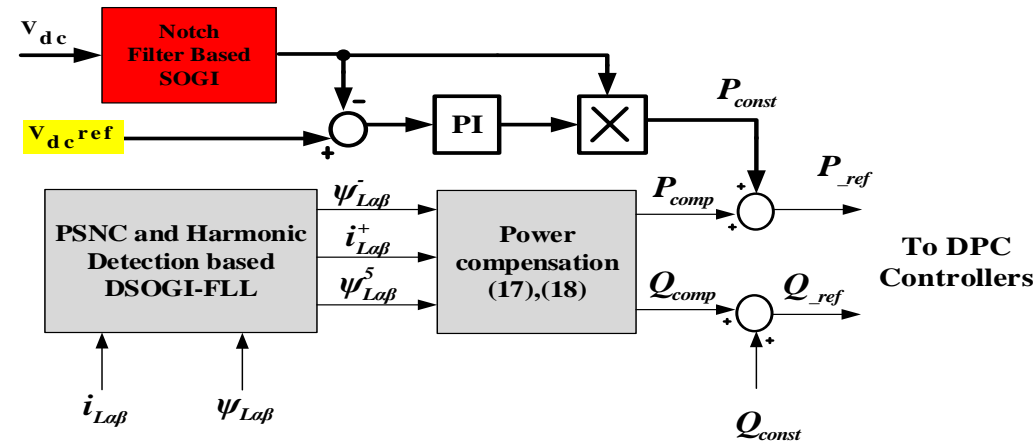

Figure 4. Control strategy under unbalance and predistortedsupply voltage

\section{SIMULATION RESULTS}

In order to verify and the validation of the proposed DPC strategy, the system has been modeled and built in MATLAB/SIMULINK software environment and tested under various conditions. The reference dc link voltage is set at $600 \mathrm{~V}$. The control of three phase rectifier aims to maintain a constant dc-link voltage, and it is controlled using VFDPC method based SOGI-FLL virtual flux estimator. Starting procedure is not relevant to this paper and not shown in the results. The main electrical parameters of the system are given in [10].

Parameters of DSOGI-FLL:

$\Gamma=100$ (gain to the settling time of the FLL block)

$\mathrm{k}=\sqrt{2}$ (gain of the SOGI)

The system is analysed during steady-state and transients conditions at three case presented in Table 1.

\begin{tabular}{|c|c|c|c|}
\hline Case & Power suply & Duration (s) & Applied method \\
\hline \multirow{2}{*}{1} & Balanced & 0 to $1 \mathrm{~s}$ & VFDPC \\
\hline & Distorsed ( $15 \%$ of $5^{\text {th }}$ harmonic and $10 \%$ of $7^{\text {th }}$ harmonic $)$ & $1.08 \mathrm{~s}$ to $1.2 \mathrm{~s}$ & M-VFDPC \\
\hline \multirow[t]{2}{*}{2} & $\begin{array}{c}\text { Unbalanced distorsed (15\% supply voltages and } 20 \% \text { of } 5^{\text {th }} \\
\text { harmonic) }\end{array}$ & $1 \mathrm{~s}$ to $1.08 \mathrm{~s}$ & VFDPC (with and without) notch filter \\
\hline & $\begin{array}{c}\text { Unbalanced distorsed } 15 \% \text { supply voltages) and } 20 \% \text { of } 5^{\text {th }} \\
\text { harmonic ) }\end{array}$ & $1.08 \mathrm{~s}$ to 1.2 & $\begin{array}{l}\text { M-VFDPC (with and without) notch } \\
\text { filter }\end{array}$ \\
\hline
\end{tabular}

Table 1. Case Simulation Study of VFDPC and M-VFDPC 


\subsection{Simulation result case 1}

The presence of the (5th and 7th) harmonics order in the grid voltage at ( $\mathrm{t}=1$ to $1.2 \mathrm{~s}$ ) Figure 5(a) creates less pulsation terms in output DC-link voltage, the frequency of the resulting oscillations is $(300 \mathrm{~Hz})$ as shown in Figure 5f. VFDPC an MVFDPC control strategy introduced very good performance under balanced or distorted voltage condition where the active power is set to their rated value without oscillation envisaged and at the same time the reactive power is maintained at zero ( $Q=0 \mathrm{VAR})$ without oscillation envisaged figure 5(d), the grid currents and estimated virtual flux takes a sinusoidal form under distorsed grid voltage conditions see Figure 5(b) \&5(e). The VFDPC based SOGI estimated scheme with improved switching table developed in [20] is able to produce almost sinusoidal phase currents with unity power factor (without using power compensation methods).
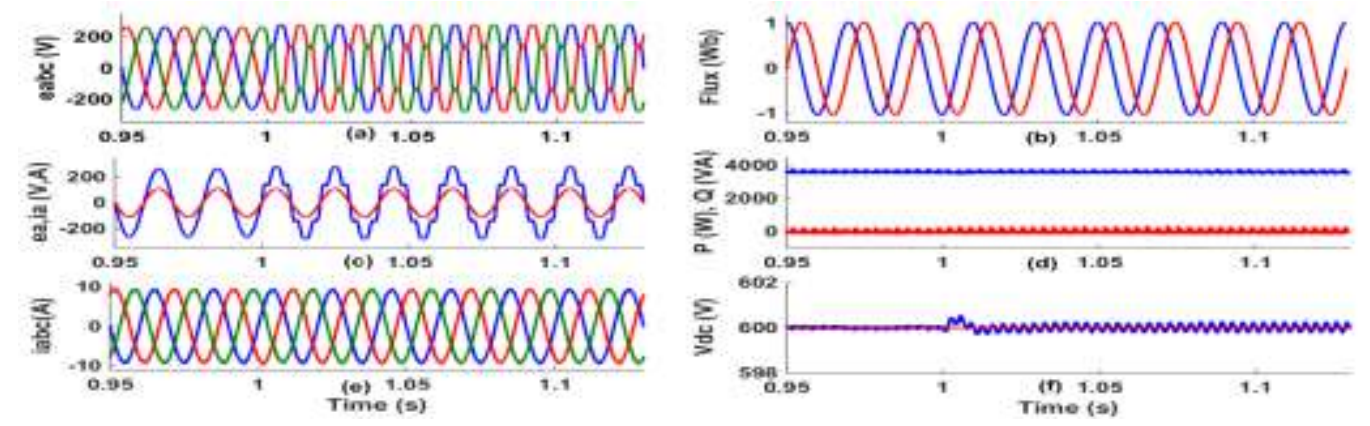

Figure 5. Simulation results from case 1 (a) Three phase voltage supply, (b) Estimated virtual flux $(\psi \stackrel{+}{+}$ and $\psi \quad \stackrel{+}{L} a$ ), (c) 1st phase voltage and current, (d) active power ( blue color) reactive power ( red color), (e) Grid currents, (f) DC link voltage in blue, reference DC voltage in red.

\subsection{Simulation result case 2}

\section{a. $\quad$ VFDPC and MFVDPC without notch filter}

Figure 6 shows the behavior of the three phase PWM rectifier controlled by the proposed strategy under totally unbalanced distorted voltage supply. At $(\mathrm{t}=0$ to $\mathrm{t}=1 \mathrm{~s})$ the line currents are very sinusoidal Figure 6(e) and the total harmonic distortion (THD) is only 3.36\% Figure 8(a), due to the excellent control ability of the VFDPC control method. However, the line currents are seriously distorted when the grid voltage is unbalanced and distorted at $(\mathrm{t}=1 \mathrm{~s}$ to $\mathrm{t}=1.08 \mathrm{~s})$, the THD is $15.65 \%$ with prominent $(3 \mathrm{th}, 5 \mathrm{th}, 7 \mathrm{th}$, 9th) order harmonic component, as shown in Figure 8(b). After integrating the power compensation schemes into the VFDPC method, the THD of the line current is reduced considerably to only $4.28 \%$, as shown in Figure 8 (c).

This demonstrates the effectiveness of the proposed MVFDPC scheme for power quality improvement. As show in Figure 6(d) at ( $\mathrm{t}=0 \mathrm{~s}$ to $\mathrm{t}=1.08 \mathrm{~s})$, all waveforms of active and reactive power are constant at, no signified ripples. However, after integrating MVFDPC compensation method without notch filter, there are many oscillations in active and reactive power. these instantaneous power oscillates at twice the grid frequency. The presence of both an unbalance and a 5th harmonic in the voltage supply creates pulsation terms in the output DC-link voltage show Figure 6(f).
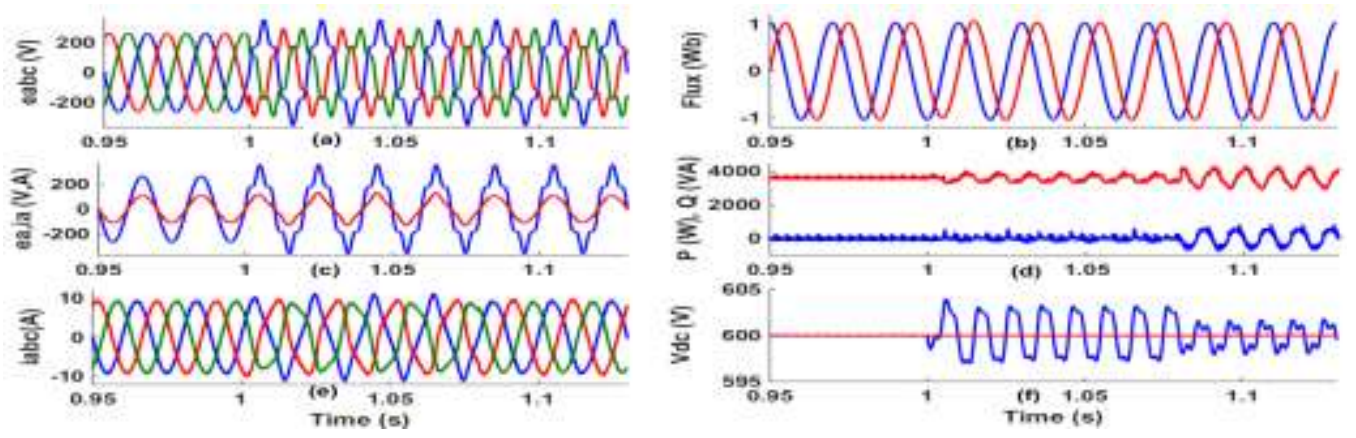

Int J Appl Power Eng, Vol. 8, No. 1, April 2019: $34-42$ 
Figure 6. Simulation results from Case2 (without notch filter), (a) three phase voltage supply, (b) Estimated

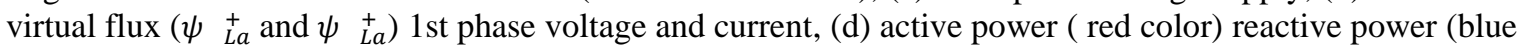
color), (e) Grid currents, (f) DC link voltage in blue, reference DC voltage in red.

b. VFDPC and MFVDPC without notch filter

In this case simulated, the notch filter gives a very good improvement in view of energy quality, less ocilation, smooth DC-link voltage and lower THD of grid currents as shown in Figure 7(c) and Figure 8(AC) respectively.
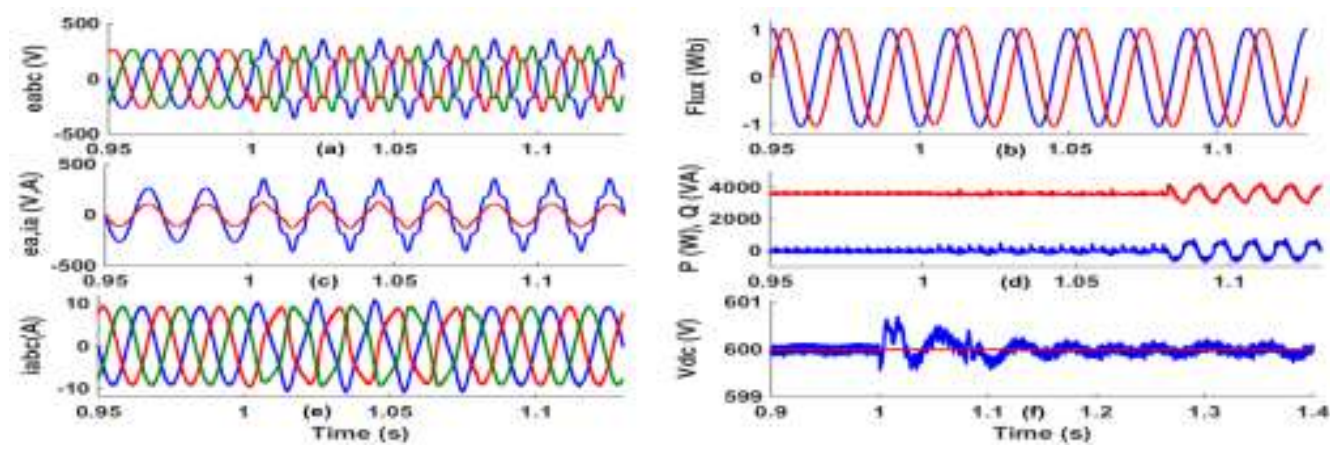

Figure 7. Simulation results from case2 (with notch filter) (a) three phase voltage supply (b) Estimated virtual

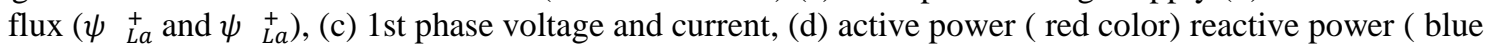
color), (e) Grid currents, (f) DC link voltage in blue, reference DC voltage in red.
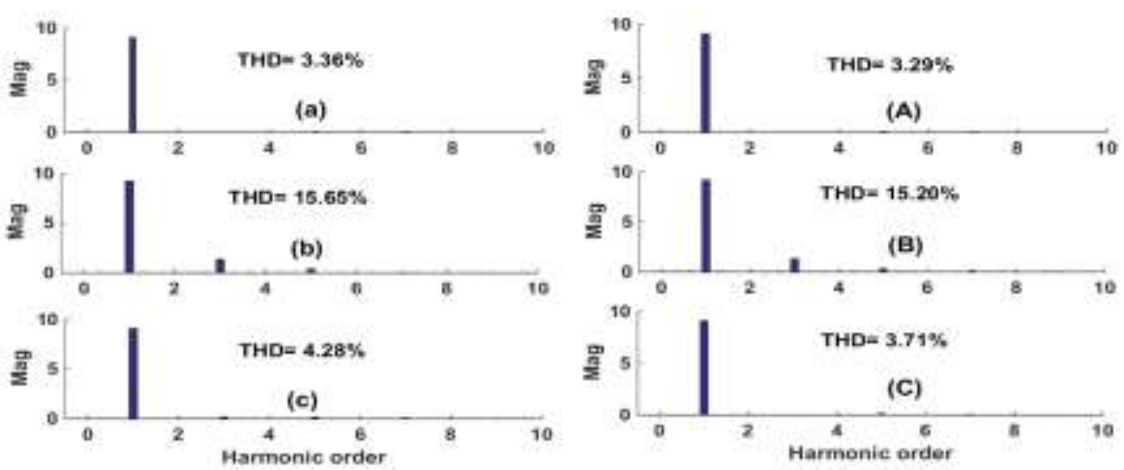

Figure 8. Spectra of grid currents in Case 2. (a) Under balanced grid voltage condition using VFDPC without notch filter, (b) Under unbalanced grid voltage condition using VFDPC without notch filter, (c) Under unbalanced grid voltage condition using MVFDPC without notch filter, (A) Under balanced grid voltage condition using VFDPC with notch filter, (B) Under unbalanced grid voltage condition using VFDPC with notch filter, (C) Under unbalanced grid voltage condition using MVFDPC with notch filter.

\section{CONCLUSION}

This paper has proposed a modified VFDPC strategy for a 3-phase PWM rectifier supplied by an disturbed voltage source. In order to obtain balanced and sinusoidal grid currents under inappropriate voltage conditions, compensated powers are calculated and added to the original reference power to achieve balanced and high quality input current.

The phase, positive, negative, harmonic sequences for voltages and currents, estimated virtual flux and notch filter scheme, are based on the SOGI-FLL technique. The proposed strategy is verified by simulation for tho cases, which are balanced/distorted voltage, and simultaneously unbalanced and distorted voltage. It proves its capability of yielding sinusoidal and balanced grid current with unity power factor under disturbed source condition. VFDPC approach in combination with a DSOGI estimator and improved switching table can address perfectly balanced/distorted grid voltage condition because this estimator is a natural filter for harmonocs; meanwhile it suffers and gives unsatisfied performance during unbalanced power supply condition.In order to overcome this disadvantage, we have proposed an MVFDPC and notch DC-link voltage filter approach with compensated powers with integrating notch DC-link voltage filter, 
obtaining a very good power quality with a satisfactory power factor, smooth and accurate DC-link voltage and a low THD factor for the input current within the standard limits whatever the power grid.

\section{REFERENCES}

[1] J. Hu, J. Zhu and D. G. Dorrell, "A comparative study of direct power control of AC/DC converters for renewable energy generation," IECON 2011 - 37th Annual Conference of the IEEE Industrial Electronics Society, Melbourne, VIC, 2011, pp. 3578-3583.

[2] Rahab A, Senani F, Benalla H., "Direct Power Control of Brushless Doubly-Fed Induction Generator Used in Wind Energy Conversion System," International Journal of Power Electronics and Drive System (IJPEDS), vol 8, no. 1, pp. 417-433, 2017.

[3] Allagui M, Hasnaoui O., "A 2 MW direct drive wind turbine vector control and direct torque control techniques comparison," Journal of Energy in Southern Africa, vol 25, no. 2, pp. 117-126, 2014.

[4] A. R. Prasad, P. D. Ziogas and S. Manias, "An active power factor correction technique for three-phase diode rectifiers," in IEEE Transactions on Power Electronics, vol. 6, no. 1, pp. 83-92, Jan. 1991.

[5] Nor Azizah Yusoff, Azziddin M. Razali, Kasrul Abdul Karim,Tole Sutikno, Auzani Jidin, "A Concept of VirtualFlux Direct Power Control of Three-Phase AC-DC Converter," International Journal of Power Electronics and Drive System (IJPEDS), vol 8, no. 4, pp. 1776- 1784, 2017.

[6] P. Verdelho and G. D. Marques, "DC voltage control and stability analysis of PWM-voltage-type reversible rectifiers," in IEEE Transactions on Industrial Electronics, vol. 45, no. 2, pp. 263-273, April 1998.

[7] Li Xiang, Han Minxiao., "Direct Virtual Power Control," TELKOMNIKA Indonesian Journal of Electrical Engineering, vol. 12, no. 7, pp. 5144- 5153, 2014.

[8] M. Mohseni, S. M. Islam and M. A. S. Masoum, "Enhanced Hysteresis-Based Current Regulators in Vector Control of DFIG Wind Turbines," in IEEE Transactions on Power Electronics, vol. 26, no. 1, pp. 223-234, Jan. 2011.

[9] T. Noguchi, H. Tomiki, S. Kondo and I. Takahashi, "Direct power control of PWM converter without power-source voltage sensors," in IEEE Transactions on Industry Applications, vol. 34, no. 3, pp. 473-479, May-June 1998.

[10] Malinowski M, Kazmierkowski M., "Simple Direct Power Control of Three-Phase PWM Rectifier Using Space Vector Modulation 'A Comparative Study," European Power Electronics and Drives. 2015 , pp. 27-34.

[11] M. Malinowski, M. P. Kazmierkowski, S. Hansen, F. Blaabjerg and G. D. Marques, "Virtual-flux-based direct power control of three-phase PWM rectifiers," in IEEE Transactions on Industry Applications, vol. 37, no. 4, pp. 1019-1027, July-Aug. 2001.

[12] Bu W, Xu L., "Direct Power Control Strategy of PWM rectifier Based onImproved Virtual Flux-Linkage observer," Journal of Control Science and Engineering, vol 2017, pp. 1-9 volume, 2017.

[13] M. B. Ketzer and C. B. Jacobina, "Sensorless Control Technique for PWM Rectifiers With Voltage Disturbance Rejection and Adaptive Power Factor," in IEEE Transactions on Industrial Electronics, vol. 62, no. 2, pp. 11401151, Feb. 2015.

[14] WU F J, Wang Z W, Sun L., "Improved virtual fluxoriented vector control of PWM rectifier," Journal Electric Machines and control, vol 5, pp. 504-508, 2008.

[15] J. A. Suul, A. Luna, P. Rodríguez and T. Undeland, "Virtual-Flux-Based Voltage-Sensor-Less Power Control for Unbalanced Grid Conditions," in IEEE Transactions on Power Electronics, vol. 27, no. 9, pp. 4071-4087, Sept. 2012.

[16] R. Zhao, Z. Xin, P. C. Loh and F. Blaabjerg, "A novel flux estimator based on SOGI with FLL for induction machine drives," 2016 IEEE Applied Power Electronics Conference and Exposition (APEC), Long Beach, CA, 2016, pp. 1995-2002.

[17] R. Zhao, Z. Xin, P. C. Loh and F. Blaabjerg, "A Novel Flux Estimator Based on Multiple Second-Order Generalized Integrators and Frequency-Locked Loop for Induction Motor Drives," in IEEE Transactions on Power Electronics, vol. 32, no. 8, pp. 6286-6296, Aug. 2017.

[18] BU W , Xu L., "Improved Virtual-Flux-Linkage Observation method of PWM Rectifier," Applied Mechanics and Materials, vol. 678, pp. 528-532, 2014.

[19] A. M. Razali, M. A. Rahman, G. George and N. A. Rahim, "Analysis and Design of New Switching Lookup Table for Virtual Flux Direct Power Control of Grid-Connected Three-Phase PWM AC-DC Converter," in IEEE Transactions on Industry Applications, vol. 51, no. 2, pp. 1189-1200, March-April 2015.

[20] A. Baktash, A. Vahedi and M. A. S. Masoum, "Improved switching table for direct power control of three-phase PWM rectifier," 2007 Australasian Universities Power Engineering Conference, Perth, WA, 2007, pp. 1-5.

[21] P. Rodriguez, A. Luna, M. Ciobotaru, R. Teodorescu and F. Blaabjerg, "Advanced Grid Synchronization System for Power Converters under Unbalanced and Distorted Operating Conditions," IECON 2006 - 32nd Annual Conference on IEEE Industrial Electronics, Paris, 2006, pp. 5173-5178.

[22] P. Rodriguez, A. Luna, I. Etxeberria, J. R. Hermoso and R. Teodorescu, "Multiple second order generalized integrators for harmonic synchronization of power converters," 2009 IEEE Energy Conversion Congress and Exposition, San Jose, CA, 2009, pp. 2239-2246.

[23] Możdżyński K, Rafał K, Bobrowska-Rafał M, "Application of the second order generalized integrator in digital control systems, " in Archives of Electrical Engineering, vol. 63, no. 3, pp. 423-437, 2014. 